\title{
SANITASI LINGKUNGAN RUMAH DAN SOSIAL BUDAYA MASYARAKAT PESISIR PANTAI TERHADAP KEJADIAN SKABIES
}

\author{
Home Environment Sanitation and Social Culture of Coastal Community \\ on the Incident of Scabies
}

\author{
Ade Irma Khairani \\ Dosen Tetap Yayasan Akper Kesdam I/BB Medan \\ email : manurungade@gmail.com
}

\begin{abstract}
Abstrak
Skabies adalah erupsi kulit yang disebabkan infestasi dan sanitisasi oleh kutu Sarcoptes Scabiei Varietas Hominis dan bermanifestasi sebagai lesi popular, pustul, vesikel. Penelitian ini bertujuan untuk menganalisa pengaruh sanitasi lingkungan rumah dan sosial budaya masyarakat pesisir terhadap kejadian skabies. Metode penelitian ini adalah deskriptif analitik dengan desain case controle. Hasil penelitian menunjukkan variabel karakteristik yang berhubungan adalah pendidikan dan pekerjaan, pada variabel sanitasi lingkungan rumah yang berhubungan dengan kejadian skabies yaitu kualitas fisik air sedangkan yang tidak berhubungan adalah kepadatan penghuni, kelembaban dan kuantitas air. Berdasarkan variabel sosial budaya masyarakat yang memiliki hubungan dengan kejadian skabies yaitu kebiasaan dan kepercayaan, sedangkan yang tidak berhubungan adalah pengetahuan dan sikap. Hasil uji regresi logistik berganda diketahui variabel yang paling dominan berpengaruh terhadap kejadian skabies adalah kebiasaan. Disarankan kepada Puskesmas meningkatkan penyuluhan tentang rumah sehat yang berkaitan dengan skabies guna mencegah terjadinya penularan skabies serta kepada masyarakat agar memebiasakan hidup bersih dan sehat.
\end{abstract}

Kata Kunci : Skabies, Sanitasi Lingkungan Rumah, Sosial Budaya Masyarakat Pesisir Pantai

\begin{abstract}
Scabies is skin eruption caused by the investment and sanitation of Sarcoptes Scabiei Varietas Hominis and manifests as popular lesions, pustules, vesicles. The purpose of this analytical descriptive study with case-control design was to analyze the influence of home environment sanitation and social culture of coastal community on the incident of scabies. The result of this study showed that the variables of characteristics which are related were education and occupation. The variables of home environment related the incident of scabies were physical quality of water while the occupant density, moisture, and water quantity did not have any relationship with the incident of scabies. Based on the variables of social culture of community, habit and belief had relationship with the incident of scabies while knowledge and attitude did not have any relationship with the incident of scabies. The result of multiple logistic regression tests showed that the most dominant variable influencing the incident of scabies was the habit. The management of Puskesmas (Community Health Center) is suggested to improve the extension on healthy house related to the incident of scabies, to prevent the spread of scabies and the community members are suggested to get used to clean and healthy life.
\end{abstract}

Keywords: Scabies, Home Environment Sanitation, Social-Culture of Community, Coastal Area 


\section{Pendahuluan}

Skabies adalah erupsi kulit yang disebabkan infestasi dan sanitisasi oleh kutu Sarcoptes Scabiei varietas hominis dan bermanifestasi sebagai lesi popular, pustul, vesikel, kadang-kadang erosi serta krusta, dan terowongan berwarna abu-abu yang di sertai keluhan subyektif sangat gatal, di temukan terutama pada daerah celah dan lipatan. Di beberapa sinonim penyakit skabies adalah the itch (inggris), gale (Perancis), Kratze (Jerman), mite infestation, gudik, budukan dan gatal agogo. ${ }^{1}$

Skabies merupakan penyakit endemik pada banyak masyarakat, penyakit ini dapat mengenai semua ras dan golongan di seluruh dunia. Penyakit ini banyak di jumpai pada anak dan orang dewasa muda, tetapi banyak mengenai semua umur. Insidens sama pada wanita dan pria. Insidens skabies di negara berkembang menunjukkan siklus fluktuasi yang sampai saat ini belum dapat di jelaskan. Interval antara akhir dari suatu epidemik dan permulaan epidemik berikutnya kurang lebih 10-15 tahun. 7

Salah satu faktor pendukung terjadinya penyakit skabies adalah sanitasi yang buruk dan dapat menyerang manusia yang hidup secara berkelompok, yang tinggal di asrama, barak-barak tentara, rumah tahanan, dan pesantren maupun panti asuhan.

Skabies terdapat di seluruh dunia dengan insiden yang berfluktuasi akibat pengaruh faktor yang belum diketahui sepenuhnya. Faktor-faktor yang mempengaruhi keberadaan penyakit ini antara lain, sosial ekonomi rendah, hygiene yang buruk, promiskuitas seksual, kepadatan penduduk dan kesalahan diagnosis dari dokter yang memeriksa. Diantara faktor di atas kepadatan penduduk merupakan faktor terpenting dalam penyebaran scabies. 10

Skabies telah menyebar ke seluruh dunia, terutama pada daerah beriklim tropis dan subtropis, penyakit ini dapat mempengaruhi semua jenis ras di dunia, meskipun demikian gambaran akurat insidensnya sulit ditemukan dengan pasti oleh karena berbagai laporan yang ada hanya berdasarkan catatan kunjungan pasien rawat jalan di rumah sakit dan puskesmas. 9

Beberapa faktor yang dapat membantu penyebarannya adalah kemiskinan, higiene yang jelek, seksual promiskuitas, diagnosis yang salah, demografi, ekologi dan derajat sanitasi individual. Insidensnya di Indonesia masih cukup tinggi, terendah di Sulawesi Utara dan tertinggi di Jawa Barat. Amiruddin dkk, dalam penelitian skabies di Rumah Sakit Dr. Soetomo Surabaya, menemukan insidens penderita skabies selama 1983-1984 adalah $2.7 \%$. Abu A dalam penelitiannya di Rumah Sakit Umum Dadi Ujung Pandang mendapatkan insidens skabies 0.67\% (1987-1988).
Lingkungan rumah adalah segala sesuatu yang berada didalam rumah. Lingkungan rumah terdiri dari lingkungan fisik yaitu ventilasi, lantai, dinding, suhu, kelembaban, pencahayaan serta lingkungan sosial yaitu kepadatan penghuni. Rumah yang ruangan terlalu sempit atau terlalu banyak penghuninya akan kekurangan oksigen menyebabkan menurunnya daya tahan tubuh yang memudahkan terjadinya penyakit. ${ }^{2}$

Usaha penyehatan lingkungan merupakan suatu pencegahan terhadap berbagai kondisi yang mungkin dapat menimbulkan penyakit dan sanitasi merupakan faktor yang utama yang harus diperhatikan.

Pengertian perumahan merupakan kelompok rumah yang berfungsi sebagai lingkungan tempat tinggal atau lingkungan hunian dan sarana pembinaan keluarga yang dilengkapi dengan prasarana dan sarana lingkungan. Sedangkan pemukiman merupakan bagian dari lingkungan hidup baik kawasan perkotaan maupun perdesaan yang berfungsi sebagai lingkungan tempat tinggal atau lingkungan hunian yang mendukung perikehidupan. Untuk menciptakan satuan lingkungan pemukiman diperlukan kawasan perumahan dalam berbagai bentuk dan ukuran dengan penataan tanah dan ruang, prasarana dan sarana lingkungan yang memenuhi kesehatan. 8

Kebudayaan adalah suatu kumpulan pedoman atau pegangan yang kegunaannya operasional dalam hal manusia mengadaptasi diri dengan dan menghadapi lingkungan-lingkungan tertentu (fisik/alam, dan sosial) agar mereka itu dapat melangsungkan kehidupannya, yaitu memenuhi kebutuhan-kebutuhannya, dan untuk dapat hidup secara lebih baik lagi. Karena itu kebudayaan juga dinamakan sebagai disain menyeluruh dari kehidupan (lihat Suparlan, 1972; 1997).Penggunaan kebudayaan oleh para pendukungnya dalam kehidupan yang nyata, yaitu bagaimana terwujud dalam tindakan-tindakan sehari-hari dalam kehidupannya sebagai warga masyarakat, terjadi karena adanya pranata-pranata sosial yang dipunyai oleh masyarakat tersebut. 5

Kebudayaan memiliki paling sedikit tiga wujud, yaitu: 1) tata kelakuan, 2) kompleks aktivitas kelakuan berpola dari manusia dalam masyarakat dan 3) sebagai benda hasil karya manusia. Wujud pertama merupakan wujud yang ideal dari kebudayaan, sifatnya abstrak, berfungsi sebagai tata kelakuan yang mengatur, mengendalikan dan memberi arah kepada kelakuan dan perbuatan. Lapisan yang paling abstrak adalah sistem nilai budaya, kemudian di ikuti oleh normanorma yang lebih konkret lagi.

Berdasarkan hasil survei pendahuluan pada bulan februari 2012, tahun 2010 skabies merupakan penyakit yang menduduki posisi ke 9 dari 10 penyakit terbesar di kota Tanjungbalai, dengan angka insidensi sebesar 4891/100.000 penduduk 
dan pada tahun 2011 menduduki posisi ke 7 sebayak 8854/100.000 penduduk. Tahun 2010 skabies merupakan kasus terbanyak di Kelurahan Pematang Pasir Kecamatan Teluk Nibung Kota Tanjungbalai yaitu menduduki posisi ke 5 dari 10 penyakit terbesar dengan insiden 343 penderita dan pada tahun 2011 menduduki posisi ke 3 dari 10 penyakit terbesar dengan insidensi 605 penderita.

Peningkatan jumlah penderita skabies terlihat jelas dari data sekunder, pada bulan Oktober 2011 yaitu ada 30 penderita, bulan November ditemukan 44 penderita dan bulan Desember menjadi 52 penderita. Dari hasil survei yang didapat ternyata mayoritas masyarakat Kelurahan Pematang Pasir bekerja sebagai nelayan dan mempunyai pendidikan rata-rata SD. Masyarakat cenderung kurang memperhatikan kebersihan lingkungan rumah serta mempunyai kebiasaan tinggal bersama satu keluarga dengan jumlah penghuni yang padat. Kebiasaan tidak langsung membawa ke puskesmas jika mengalami gangguan kesehatan tapi hanya sekedar membeli obat di warung, misalnya ada gejala penyakit kulit seperti gatal-gatal atau kudis, masyarakat pesisir tidak langsung membawa ke puskesmas tapi membuat obat sendiri dari bahan-bahan tradisional, jika tidak bisa teratasi dengan obat tradisional baru kemudian masyarakat membawa ke mantri atau puskesmas. Beberapa anggota masyarakat dikalangan kelompok yang beragama islam percaya bahwa anak adalah titipan tuhan, dan sakit atau mati itu adalah takdir, sehingga masyarakt kurang berusaha untuk segera mencari pertolongan pengobatan bagi anaknya yang sakit.

Kondisi air pantai sangat mengganggu masyarakat Pematang Pasir, karena adanya proses pasang surut. Jika air pasang, air pasti sampai ke halaman rumah sehingga halaman tenggelam. Keadaan lingkungan yang tidak higienes dan tidak tertata dengan baik, sulitnya air bersih dan adanya kebiasaan sebahagian masyarakat mandi, mencuci dan kakus (MCK) di pantai.

\section{Metode}

Jenis penelitian ini adalah studi observasional dengan rancangan penelitian case controle. Penelitian dilakukan pada bulan Juni Juli 2012. Populasi dari penelitian ini adalah seluruh penderita penyakit kulit yang datang ke Puskesmas Pematang Pasir Kecamatan Teluk Nibung Kota Tanjungbalai dari bulan Oktober Desember 2011 sebanyak 211 penderita yang terdiri dari kelompok kasus sebanyak 126 penderita dan kelompok kontrol sebanyak 85 penderita. Jumlah sampel dalam penelitian ini ditetapkan 1:1, dimana kasus 52 responden dan control 52 responden, maka total sampel dalam penelitian ini adalah 104 responden. Teknik pengambilan sampel kasus dan kontrol dalam penelitian ini adalah dengan menggunakan purposive sampling. Pengumpulan data dilakukan dengan cara data primer melalui wawancara langsung kepada responden dengan menggunakan pedoman kuesioner dan hasil kualitas fisik air yang di uji di laboratorium kimia BTKL. Data sekunder diperoleh dari pencatatan dan laporan Puskesmas Pematang Pasir Kecamatan Teluk Nibung Kota Tajungbalai.

\section{Hasil}

\section{Karakteristik Responden}

Secara rinci distribusi responden berdasarkan jenis kelamin, pendidikan dan pekerjaan dapat dilihat pada tabel 1.berikut ini:

Tabel 1. Karakteristik Responden

\begin{tabular}{llllc}
\hline \multirow{2}{*}{$\begin{array}{l}\text { Distribusi } \\
\text { Frekuensi }\end{array}$} & \multicolumn{2}{c}{$\begin{array}{c}\text { Status } \\
\text { Responden }\end{array}$} & \multicolumn{2}{c}{ Total } \\
\cline { 2 - 5 } & + & - & N & $\%$ \\
\hline $\begin{array}{l}\text { Jenis kelamin } \\
\text { Laki-laki }\end{array}$ & 52 & 52 & 104 & 100,0 \\
\hline Pendidikan & & & & \\
PT & 0 & 12 & 12 & 11.5 \\
SLTA & 7 & 20 & 27 & 26.0 \\
SLTP & 45 & 20 & 65 & 62.5 \\
\hline Pekerjaan & & & & \\
Nelayan & 28 & 39 & 75 & 64.4 \\
Karyawan & 21 & 5 & 26 & 25.0 \\
Peg. swasta & 3 & 8 & 11 & 10.6 \\
\hline
\end{tabular}

\section{Sanitasi Lingkungan Rumah}

Secara rinci distribusi sanitasi lingkungan rumah responden berdasarkan kepadatan penghuni, kelembaban dan ketersediaan air bersih (kuantitas dan kualitas fisik air) dapat dilihat pada tabel 2 . berikut ini

Tabel 2. Sanitasi Lingkungan Rumah

\begin{tabular}{lllll}
\hline $\begin{array}{l}\text { Distribusi } \\
\text { Frekuensi }\end{array}$ & \multicolumn{2}{l}{$\begin{array}{l}\text { Status } \\
\text { Responden }\end{array}$} & \multicolumn{2}{l}{ Total } \\
\cline { 2 - 5 } & + & - & n & $\%$ \\
\hline $\begin{array}{l}\text { Kepadatan } \\
\text { penghuni }\end{array}$ & & & & \\
$\begin{array}{l}\text { Tidak memenuhi } \\
\text { syarat }\end{array}$ & 42 & 35 & 77 & 74,0 \\
Memenuhi syarat & 10 & 17 & 27 & 26,0 \\
\hline $\begin{array}{l}\text { Kelembaban } \\
\text { Tidak memenuhi } \\
\text { syarat }\end{array}$ & 22 & 19 & 41 & 39,4 \\
Memenuhi syarat & 30 & 33 & 63 & 60,6 \\
\hline $\begin{array}{l}\text { Kuantitas } \\
\text { Tidak memenuhi } \\
\text { syarat }\end{array}$ & 19 & 21 & 40 & 38,5 \\
Memenuhi syarat & 33 & 31 & 64 & 61,5 \\
\hline $\begin{array}{l}\text { Kualitas fisik } \\
\text { air }\end{array}$ & & & &
\end{tabular}


Tidak memenuhi

\begin{tabular}{lllll} 
syarat & 39 & 22 & 61 & 58,7 \\
Memenuhi syarat & 13 & 30 & 43 & 41,3 \\
\hline
\end{tabular}

\section{Sosial Budaya Masyarakat Pesisir}

Secara rinci distribusi sosial budaya masyarakat pesisir berdasarkan pengetahuan, kebiasaan, sikap dan kepercayaan/keyakinan dapat dilihat pada tabel 3 . berikut ini:

Tabel 3. Sosial Budaya Masyarakat Pesisir

\begin{tabular}{llccc}
\hline \multirow{2}{*}{$\begin{array}{l}\text { Distribusi } \\
\text { Frekuensi }\end{array}$} & \multicolumn{2}{l}{$\begin{array}{l}\text { Status } \\
\text { Responden }\end{array}$} & \multicolumn{2}{c}{ Total } \\
\cline { 2 - 5 } & + & - & n & $\%$ \\
\hline $\begin{array}{l}\text { Pengetahuan } \\
\text { Buruk }\end{array}$ & 32 & 35 & 67 & 64,4 \\
Baik & 20 & 17 & 37 & 35,6 \\
\hline Tabel 3. Lanjutan & & & \\
\hline Kebiasaan & & & & \\
Buruk & 34 & 22 & 56 & 58,3 \\
Baik & 18 & 30 & 48 & 46,2 \\
\hline Sikap & 22 & 20 & 42 & 40,4 \\
Buruk & 30 & 32 & 62 & 59,6 \\
Baik & & & & \\
\hline Kepercayaan & 30 & 19 & 49 & 47,1 \\
Buruk & 22 & 33 & 55 & 52,9 \\
Baik & & &
\end{tabular}

Jurnal Riset Hesti Medan, Vol. 1, No. 1 Juni 2016

\begin{tabular}{lllll} 
Variable & B & Sig & $\begin{array}{l}\mathbf{E x p} \\
(\boldsymbol{\beta})\end{array}$ & $\mathbf{9 5 \%}$ \\
\hline Kualitas & $-1,297$ & 0,003 & 0,273 & $\begin{array}{l}- \\
\text { fisik air }\end{array}$ \\
& & & & 0,640 \\
Kebiasaaan & $-0,767$ & 0,042 & 0,464 & $\begin{array}{l}0,202 \\
- \\
\end{array}$ \\
Constanta & $\mathbf{1 , 1 8 5}$ & $\mathbf{0 , 0 0 3}$ & $\mathbf{3 , 2 7 0}$ & \\
\hline
\end{tabular}

Variabel yang paling dominan memengaruhi kejadian skabies adalah variabel kebiasaan dengan nilai koefisien tertinggi (Exp. $\boldsymbol{\beta}=$ $0,464)$ diikuti variabel kualitas fisik air dengan nilai (Exp. $\boldsymbol{\beta}=0,273$ ).

\section{Pembahasan}

Kepadatan penghuni rumah dalam penelitian ini adalah perbandingan antara luas lantai rumah responden dengan jumlah anggota keluarga yang tinggal dalam satu rumah, memenuhi syarat kesehatan jika $\geq 4 \mathrm{~m}^{2} /$ orang atau dalam kategori memenuhi syarat.

Hasil penelitian menunjukkan tidak ada hubungan kepadatan penghuni rumah dengan kejadian skabies Hasil penelitian ini sesuai dengan hasil penelitian yang dilakukan oleh Putri (2007) yang mengatakan tidak ada hubungan kepadatan penghuni dengan kejadian skabies berbeda dengan hasil penelitian Hidayati (2004) dan Widyantana (2010) mengatakan ada hubungan antara kepadatan penghuni dengan kejadian skabies.

Skabies terdapat di seluruh dunia dengan insiden yang berfluktuasi akibat pengaruh faktor yang belum diketahui sepenuhnya. Faktor-faktor yang memengaruhi keberadaan penyakit ini antara lain, sosial ekonomi rendah, hygiene yang buruk, promiskuitas seksual, kepadatan penduduk dan kesalahan diagnosis dari dokter yang memeriksa. Diantara faktor di atas kepadatan penduduk merupakan faktor terpenting dalam penyebaran skabies.

Persyaratan kelembaban untuk kesehatan di lingkungan industri adalah berkisar antara 40$60 \%$ (memenuhi syarat) dan $<40-60 \%$ (tidak memenuhi syarat).

Hasil penelitian menunjukkan tidak ada hubungan kelembaban dengan kejadian skabies Hasil penelitian ini berbeda dengan hasil penelitian yang dilakukan oleh Frenki (2011) yang mengatakan ada hubungan kelembaban dengan kejadian skabies, berbeda dengan hasil penelitian Kristiwiani (2005) mengatakan tidak ada hubungan antara kelembaban dengan kejadian skabies.

Kelembaban merupakan sarana baik untuk pertumbuhan mikroorganisme. Kelembaban rumah yang tinggi dapat memengaruhi penurunan daya tahan tubuh seseorang dan meningkatkan kerentanan tubuh terhadap penyakit 51 ima penyakit infeksi. Kelembaban ju 51 ıpat meningkatkan daya tahan hidup bakteri.

Berdasarkan variabel kuantitas air diukur dengan dua kategori yaitu memenuhi syarat $(\geq 100$ liter/orang/hari) dan tidak memenuhi syarat $(\leq 100$ liter/orang/hari).

Hasil penelitian menunjukkan tidak ada hubungan kuantitas air dengan kejadian skabies. Hasil penelitian ini berbeda dengan hasil penelitian Lusiana (2004), Frenki (2011) dan Faisal (2010) bahwa kuantitas air mempunyai hubungan dengan kejadian skabies.

Rata-rata pemakaian air di Indonesia 100 liter/orang/hari dengan perincian 5 liter untuk air minum, 5 liter untuk air masak, 15 liter untuk mencuci, 30 liter untuk mandi dan 45 liter digunakan untuk jamban.

Air merupakan komponen lingkungan yang penting bagi kehidupan manusia, karena tanpa air manusia tidak dapat hidup. Namun demikian air dapat menjadi malapetaka, bilamana tidak tersedia dalam kondisi yang benar baik kuantitas maupun kualitasnya. Pertumbuhan penduduk dan kegiatan manusia menyebabkan pencemaran sehingga kualitas air yang baik dan memenuhi persyaratan tertentu sulit diperoleh.3

Berdasarkan data kualitas fisik air diukur dengan dua kategori yaitu memenuhi syarat dan 
tidak memenuhi syarat. Hasil penelitian menunjukkan ada hubungan kualitas fisik air dengan kejadian skabies. Hasil penelitian ini sama dengan hasil penelitian yang dilakukan oleh Faisal (2010), Ma'rufi (2005), Lusiana (2004) mengatakan ada hubungan kualitas fisik air dengan kejadian skabies, berbeda dengan hasil penelitian Kristiwiani (2005), Putri (2011) mengatakan tidak ada hubungan kualitas fisik air dengan kejadian skabies. Secara fisik air bisa dirasakan oleh lidah, air yang terasa asam, manis, pahit atau asin menunjukkan bahwa kualitas air tersebut tidak baik. Rasa asin disebabkan oleh garam-garam tertentu yang larut dalam air, sedangkan rasa asam diakibatkan adanya asam organik maupun asam anorganik.

Air untuk rumah tangga harus jernih, air yang berwarna berarti mengandung bahan-bahan lain yang berbahaya bagi kesehatan. 6

Skala pengukuran menurut Pratomo (1990), skala pengukuran untuk pengetahuan dapat dikategorikan pengetahuan baik, jika menjawab pertanyaan dengan benar $\geq 75 \%$ dari nilai tertinggi, pengetahuan buruk jika menjawab pertanyaan dengan benar $\leq 40 \%$ dari nilai tertinggi.

Hasil penelitian menunjukkan tidak ada hubungan pengetahuan responden dengan kejadian skabies. Asumsi penulis, jika pengetahuan tinggi maka akan memengaruhi perilaku hidup seseorang, khususnya dalam kontes kesehatan yaitu memengaruhi untuk mengalami kejadian skabies. Hasil penelitian ini tidak sesuai dengan hasil penelitian Somad (2006) yang menyatakan bahwa pengetahuan mempunyai hubungan dengan kejadian skabies, jika pengetahuan tinggi terutama pengetahuan tentang skabies maka akan mengurangi angka kejadian skabies.

Analisis variabel kebiasaan diperoleh hasil uji statistik chi square ada hubungan pengetahuan responden dengan kejadian skabies. Penulis berasumsi bahwa kebiasaan seseorang sangat memengaruhi kejadian skabies, terutama kebiasan hidup yang tidak sehat, hidup jorok yaitu kurang memperhatikan kebersihan lingkungan rumah, lingkungan sekitar dan terutama personal hygiene yang buruk. Hasil penelitian ini sesuai dengan hasil penelitian Somad (2006) yang menyatakan bahwa kebiasaan mempunyai hubungan dengan kejadian skabies, jika kebiasaan baik terutama kebiasaan hidup bersih dan sehat maka akan mengurangi angka kejadian skabies.

Analisis variabel sikap diperoleh tidak ada hubungan sikap dengan kejadian skabies. Penulis berasumsi bahwa sikap seseorang sangat memengaruhi kejadian skabies, terutama sikap yang buruk, perilaku hidup jorok yaitu kurang memperhatikan kebersihan lingkungan rumah, lingkungan sekitar dan terutama personal hygiene buruk. Hasil penelitian ini sesuai dengan hasil penelitian Nugraheni (2008) yang menyatakan bahwa sikap mempunyai hubungan dengan kejadian skabies, jika sikap baik terutama sikap dalam mencegah kejadian skabies maka akan mengurangi angka kejadian skabies.

Hasil penelitian menunjukkan variabel kepercayaan ada hubungan dengan kejadian skabies. Penulis berasumsi bahwa kepercayaan/keyakinan seseorang sangat memengaruhi kejadian skabies, terutama kepercayaan/keyakinan seseorang yang kurang mempercayai dan bahkan tidak mempercayai akan adanya penyakit skabies, dan dampak buruk dari perilaku tidak sehat.

Berdasarkan uji regresi logistik berganda dari 10 (sepuluh) variabel yang diteliti diperoleh hasil bahwa variabel yang paling berpengaruh terhadap kejadian skabies adalah variabel kebiasaan dengan nilai koefisien tertinggi $(\operatorname{Exp} . \boldsymbol{\beta}=$ 0,464).

Berdasarkan hasil penelitian diatas maka dapat diketahui bahwa jika responden memiliki kebiasaan buruk maka semakin besar peluang terjadinya skabies. Hal ini dapat dilihat dari data bahwa sebagian besar responden kelompok kasus (skabies positif) di Kelurahan Pematang Pasir mempunyai kebiasaan buruk, sehingga dapat menyebabkan terjadinya skabies pada responden.

Berdasarkan uraian diatas dapat disimpulkan bahwa mayoritas responden memiliki kebiasaan buruk, sehingga dapat meneyebabkan terjadinya skabies terutama pada kelompok kasus (skabies positif). Semakin banyak responden yang memiliki kebiasaan buruk maka akan semakin memengaruhi angka kejadian skabies.

Skabies adalah erupsi kulit yang disebabkan infestasi dan sanitisasi oleh kutu Sarcoptes Scabiei varietas hominis dan bermanifestasi sebagai lesi popular, pustul, vesikel, kadang-kadang erosi serta krusta, dan terowongan berwarna abu-abu yang di sertai keluhan subyektif sangat gatal, di temukan terutama pada daerah celah dan lipatan. Di beberapa sinonim penyakit skabies adalah the itch (inggris), gale (Perancis), Kratze (Jerman), mite infestation, gudik, budukan dan gatal agogo.

\section{Kesimpulan}

Berdasarkan variabel sanitasi lingkungan rumah yang memiliki hubungan terhadap kejadian skabies yaitu variabel kualitas fisik air, sedangkan variabel yang tidak memiliki pengaruh adalah kepadatan penghuni, kelembaban dan variabel kuantitas air. Berdasarkan variabel sosial budaya masyarakat, yang memiliki pengaruh terhadap kejadian skabies yaitu variabel kebiasaan dan kepercayaan sedangkan variabel yang tidak memiliki pengaruh adalah variabel pengetahuan, kebiasaan dan sikap. Berdasarkan variabel karakteristik responden, semua variabel memiliki pengaruh terhadap kejadian skabies yaitu variabel pendidikan dan 
variabel pekerjaan. Variabel yang paling dominan berpengaruh terhadap kejadian skabies adalah kebiasaan dengan nilai koefisien tertinggi (Exp. $\boldsymbol{\beta}=$ $0,464)$.

\section{Daftar Pustaka}

Boediardja, A. S., dkk., 2004. Infeksi Kulit Pada Anak dan Bayi. Jakarta: Fakultas Kedokteran Indonetion University

Chandra, B., 2007. Pengatar Kesehatan Lingkungan. Jakarta: EGC

Effendi, H. 2003. Telaah Kualitas Air. Yokyakarta. Kanisius.

Koentjaraningrat., 2003. Pengantar Antropologi. Yogyakarta: Jakarta: Djambatan.

Kusnadi., 2007. Jurnal Sosial Budaya Ekonomi Masyarakt Pesisir Pantai, Pesisir Laut, Vol 2 No. 2. Januari 2007.
Mariana, 2004. Kualitas Fisik dan Kimia Air PAM di Jakarta, Bogor, Tangerang dan Bekasi tahun 1999-2001.

Makatutu., 2004. Ilmu Penyakit Kulit. Jakarta: PT. Gramedia

Mukono, H. J., 2002. Environmental Epidemiologi. Surabaya: Airlangga Universitas.

Noor, N. N., 2000. Pengantar Epidemiologi Penyakit Menular. Jakarta: Rineka Cipta

Sastroasmoro \& Ismael., 2008. Dasar-dasar Metodologi Penelitian Klinis. Edisi ke tiga. Jakarta. 